\title{
FAUNA E FLORA URBANA Ensaio Fotográfico
}

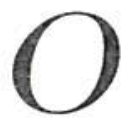

ensaio fotográfico que segue resulta do projeto "Fauna e flora urbana", desenvolvido em conjunto pelo Laboratório de Estudos Urbanos da Unicamp (Labeurb) e pelo Núcleo de Fotografia de Campinas (NFC). As imagens mostram áreas verdes e aves de Campinas e região.

Já são bastante difundidos os trabalhos fotográficos que representam elementos da fauna e da flora em seu ambiente natural. Este conjunto de fotos, por sua vez, retrata esses elementos dentro do contexto urbano, inseridos na materialidade da cidade. Colocam-se em relação, em um vai-e-vem constante, os discursos e as imagens sobre a/da cidade. $\mathrm{O}$ conhecimento do urbano se produz, assim, nesse espaço intervalar, em que o visual e o verbal se entrecruzam. As imagens suscitam, entre outras coisas, uma discussão sobre a relação natural-social, sobre as políticas ambientais (ver o artigo "Os desafios da ecologia urbana" nesta revista), sobre as paisagens da cidade, sobre os empecilhos para a flora urbana (construção civil, fiação), bem como sobre o posicionamento do fotógrafo diante destas questões, nos limites entre o desenvolvimento temático e as possibilidades formais, técnicas e estéticas.

\section{Participantes:}

Do Laboratório de Estudos Urbanos: JOSÉ HORTA NUNES

Do Núcleo de Fotografia de Campinas:

SILNEI MARTINS ANTÔNIO CARLOS CÂNDIDO

RENATO A. M. SILVANO

ROBERTO MERCURY 



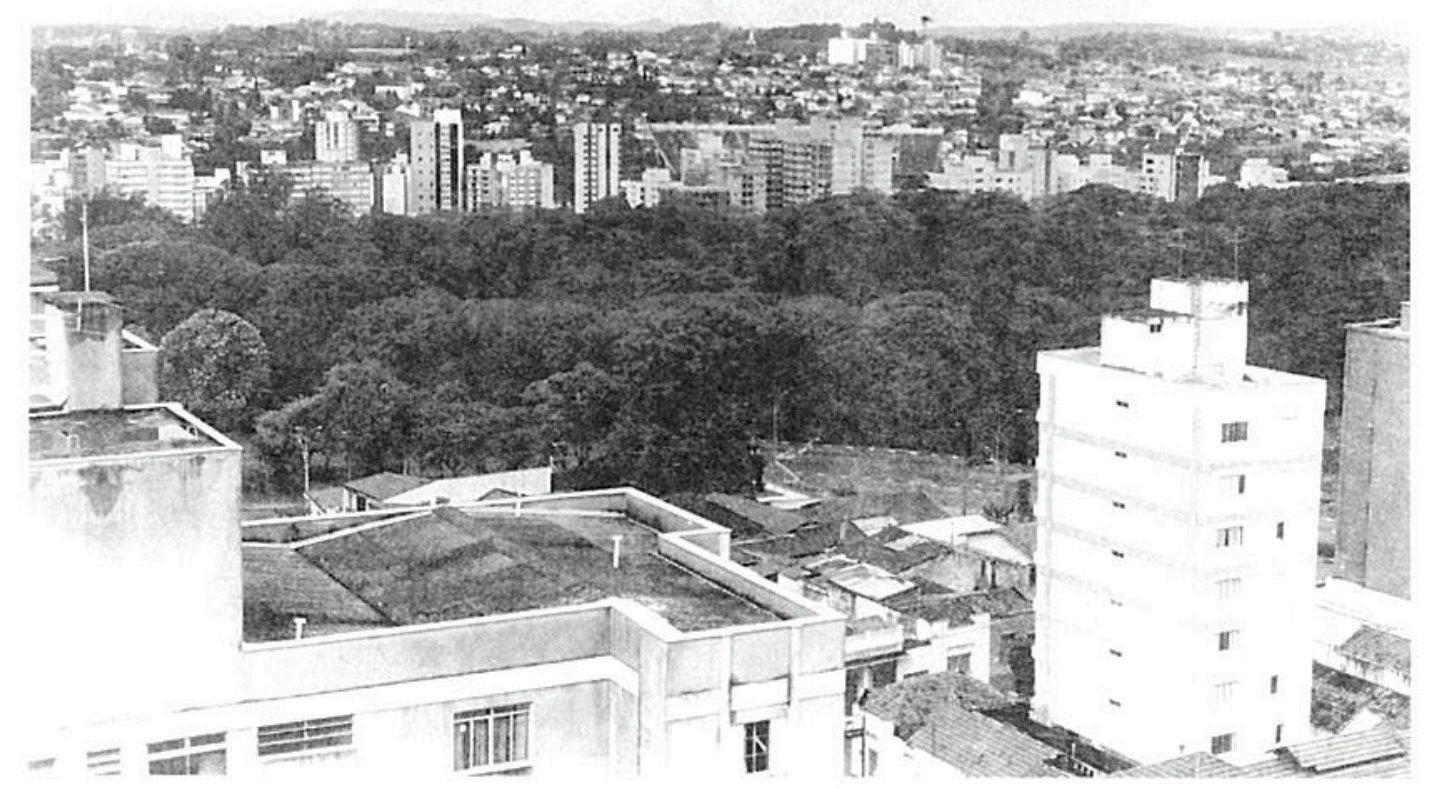

1. Bosque dos Jequitibás - Campinas Fot. SILNEI MARTINS 


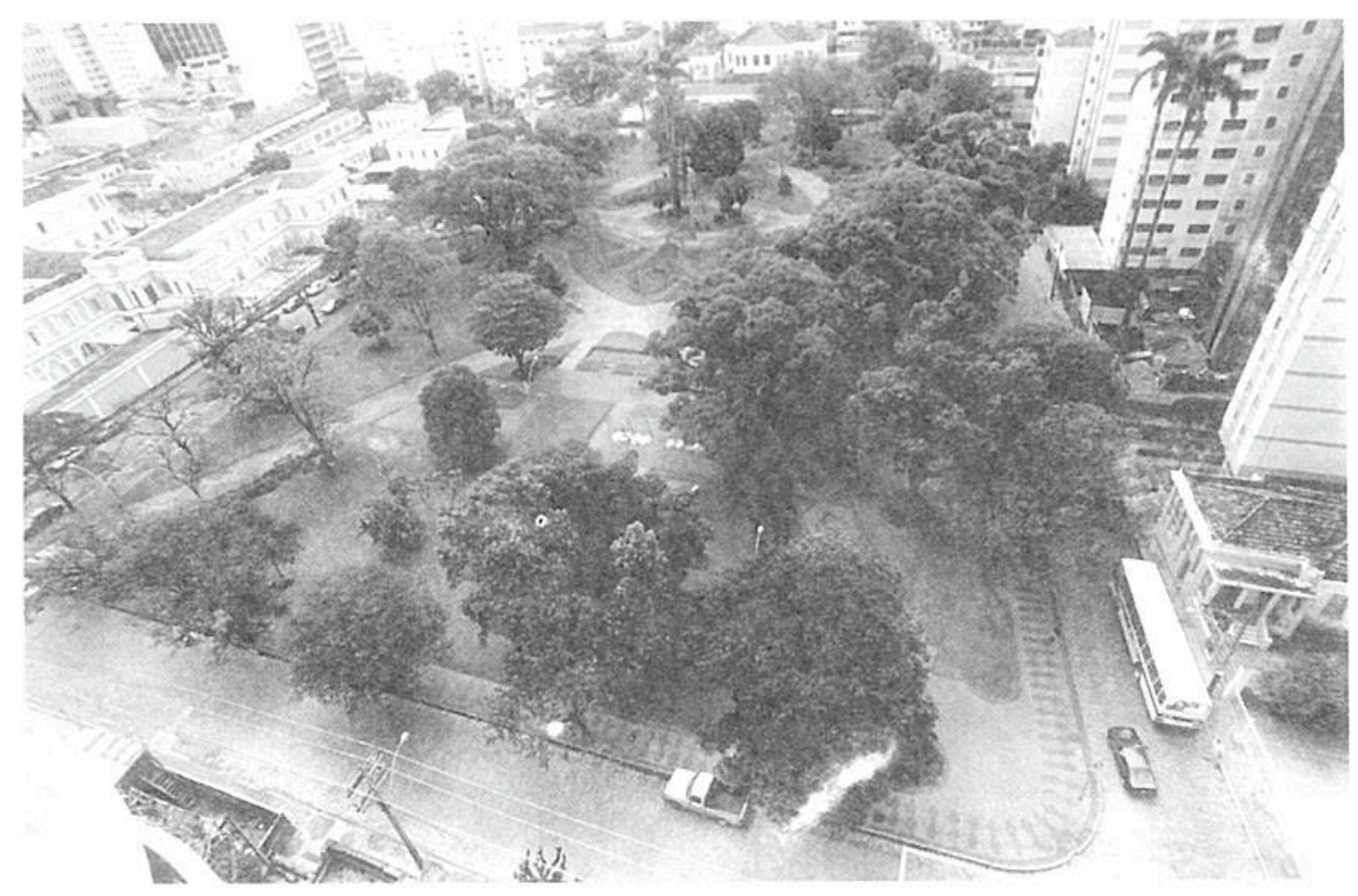

2. Largo São Benedito - Campinas Fot. SILNEI MARTINS 


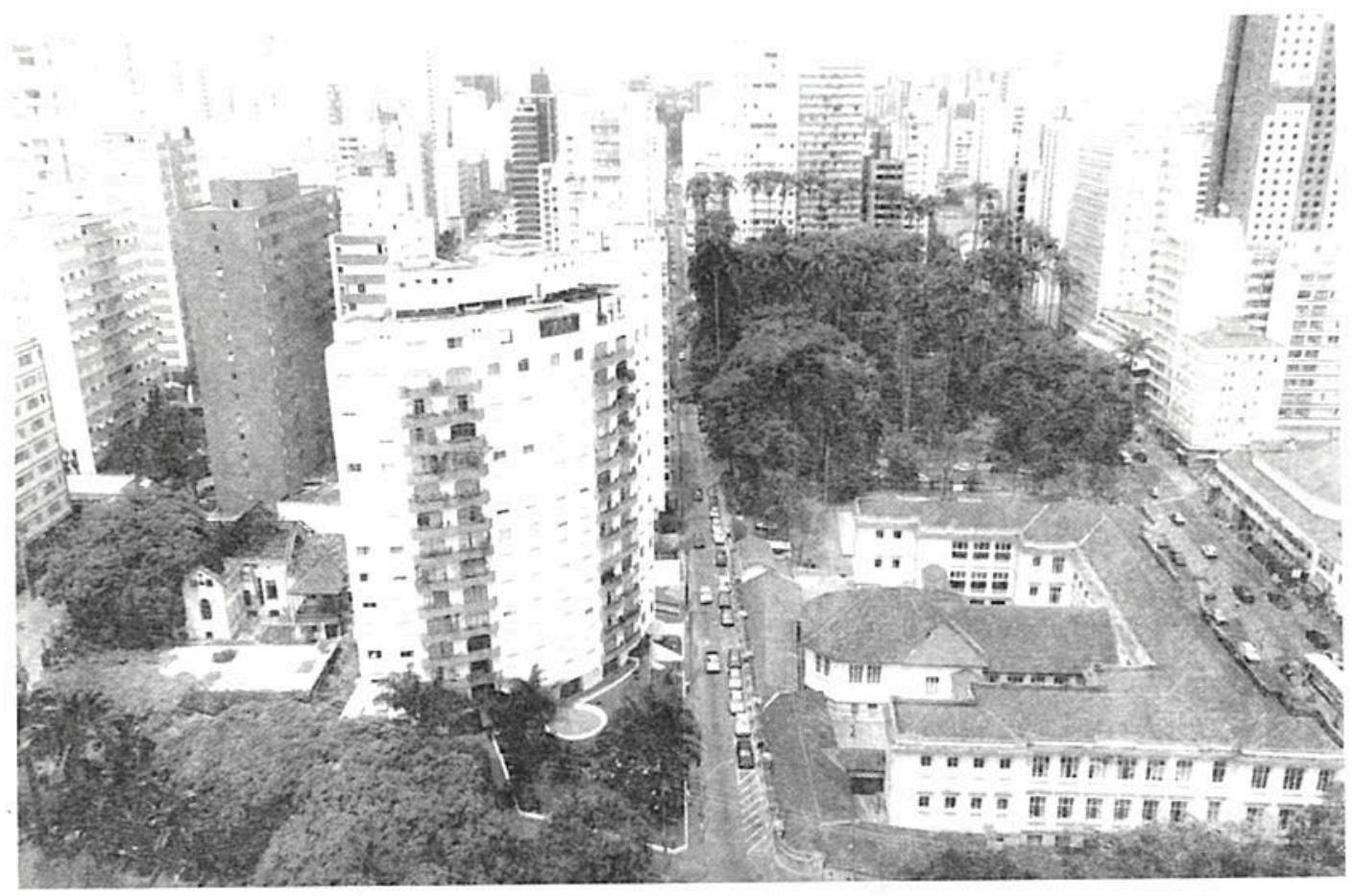

3. Praça Carlos Gomes e Centro de Campinas Fot. ROBERTO MERCURY 


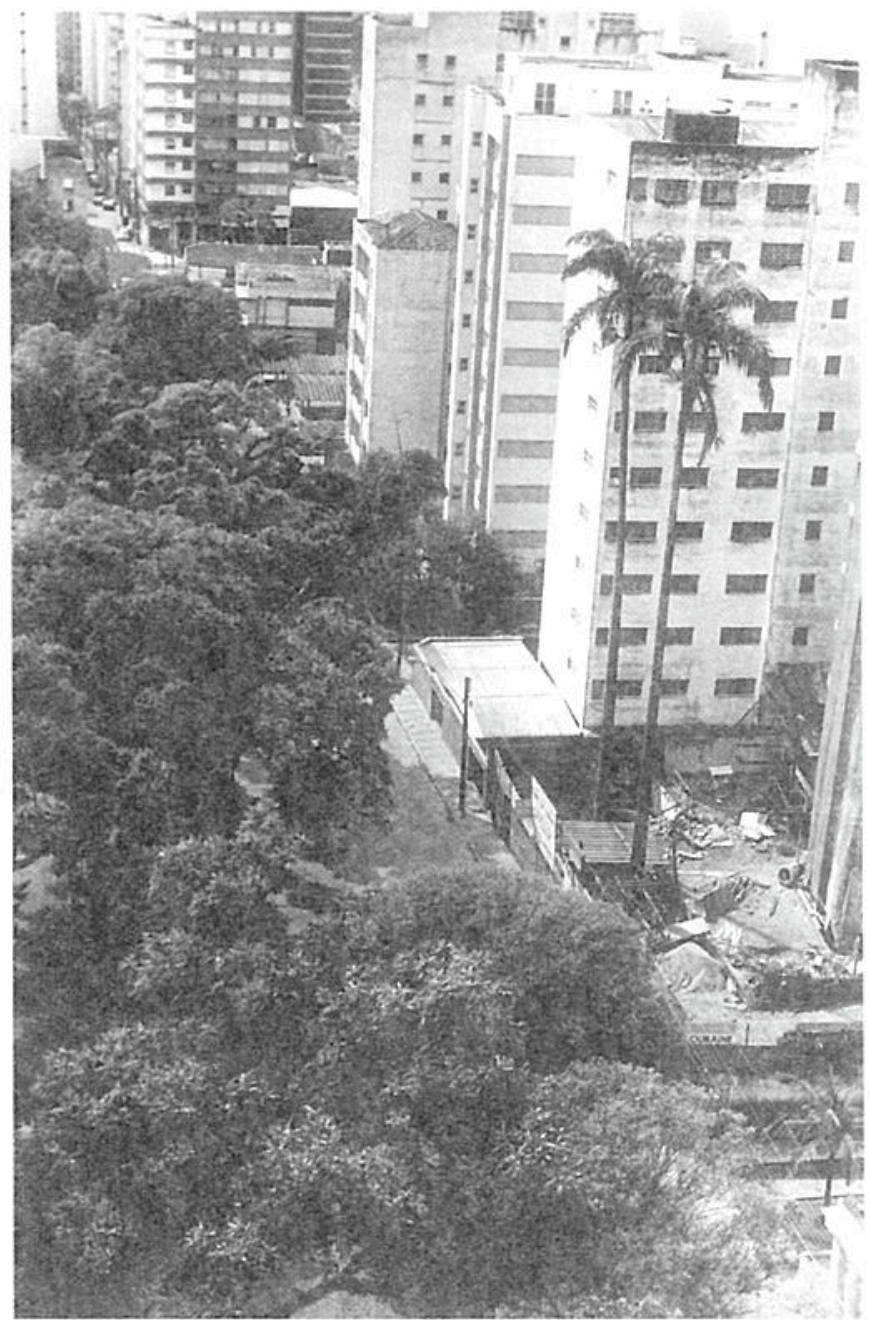

4. Fot. SILNEI MARTINS 


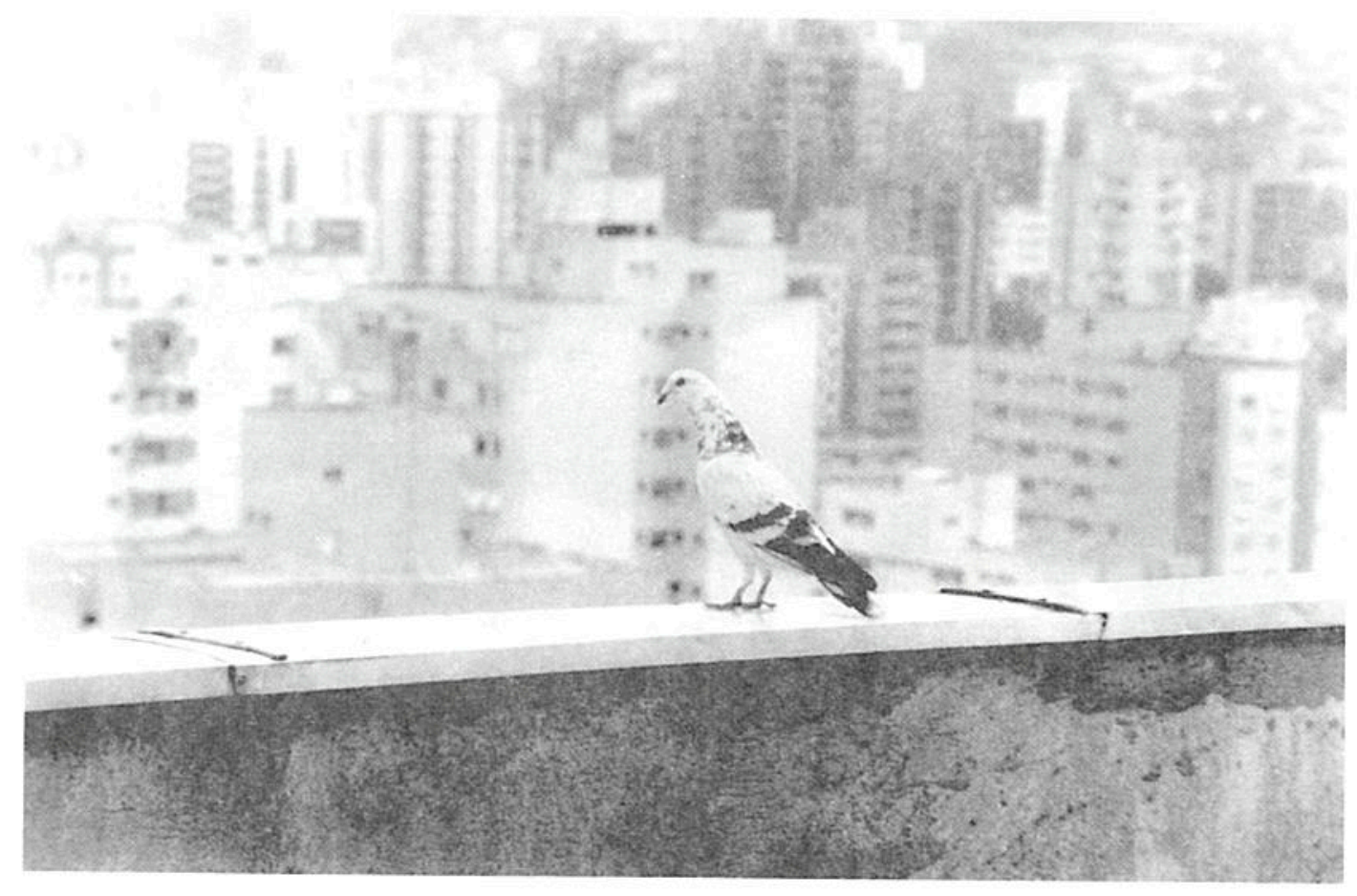

5. Fot. ROBERTO MERCURY 


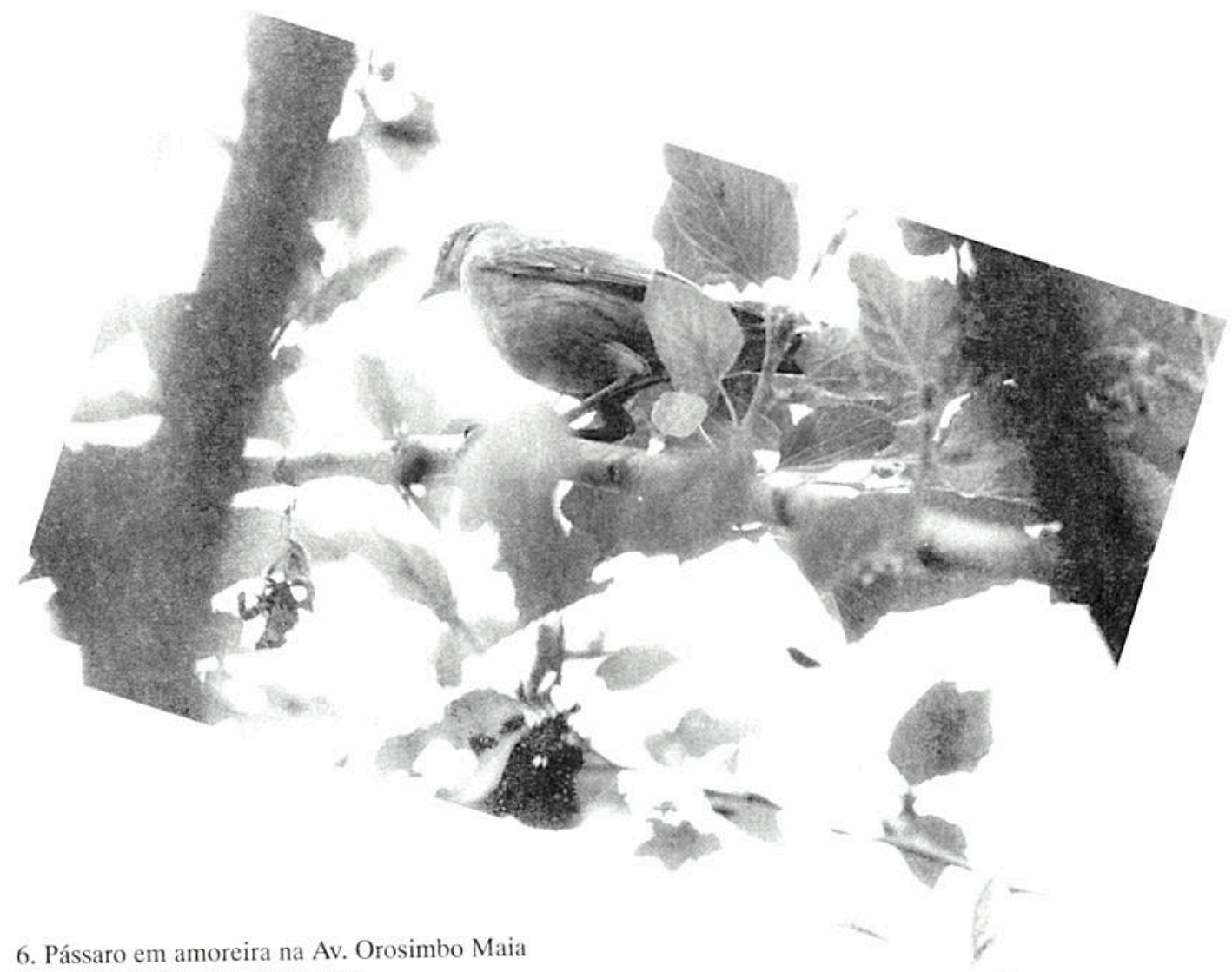

Fot. RENATO A. M. SILVANO 


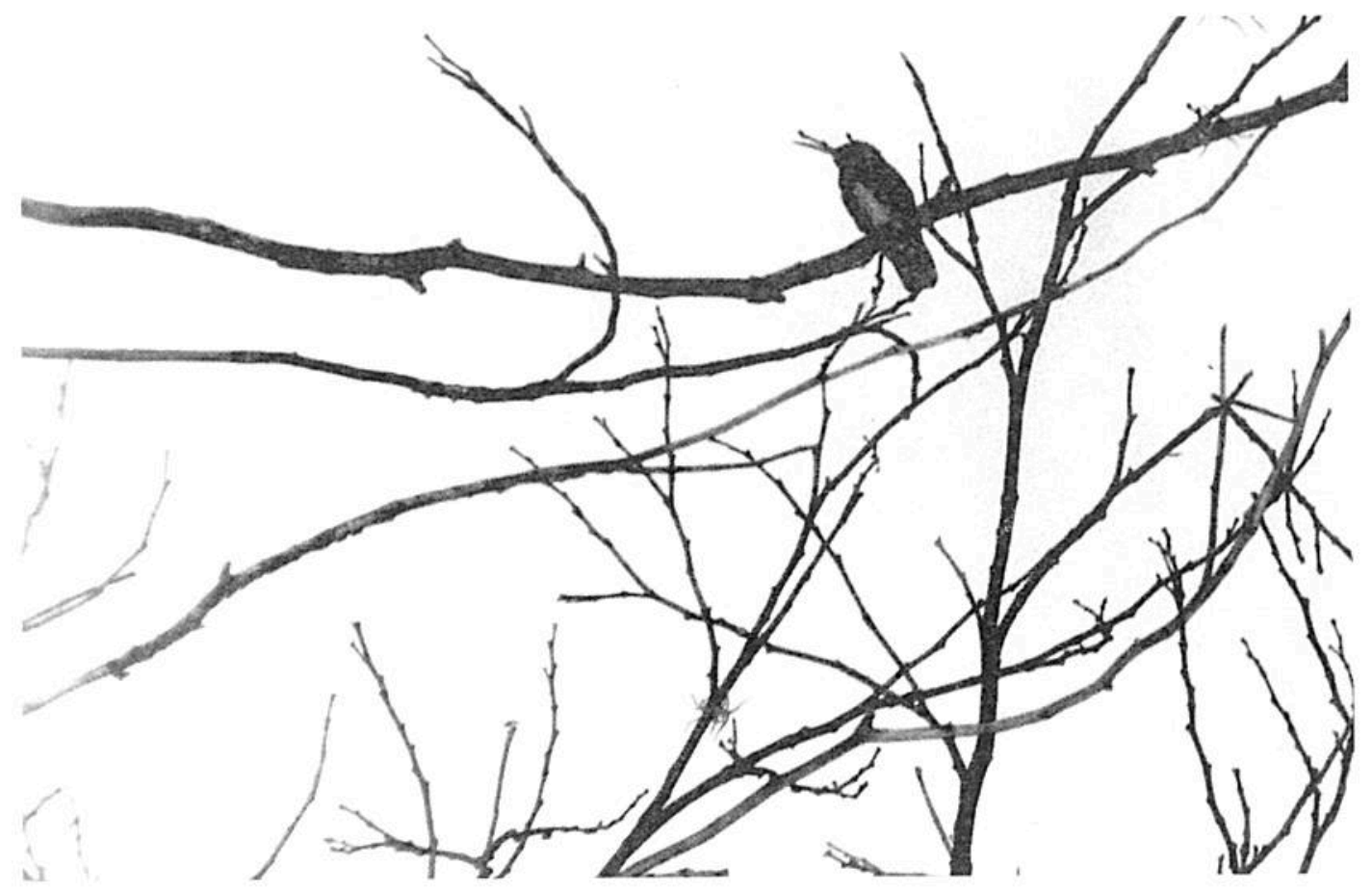

7. Beija-flor fotografado na Unicamp

Fot. RENATO A. M. SILVANO 


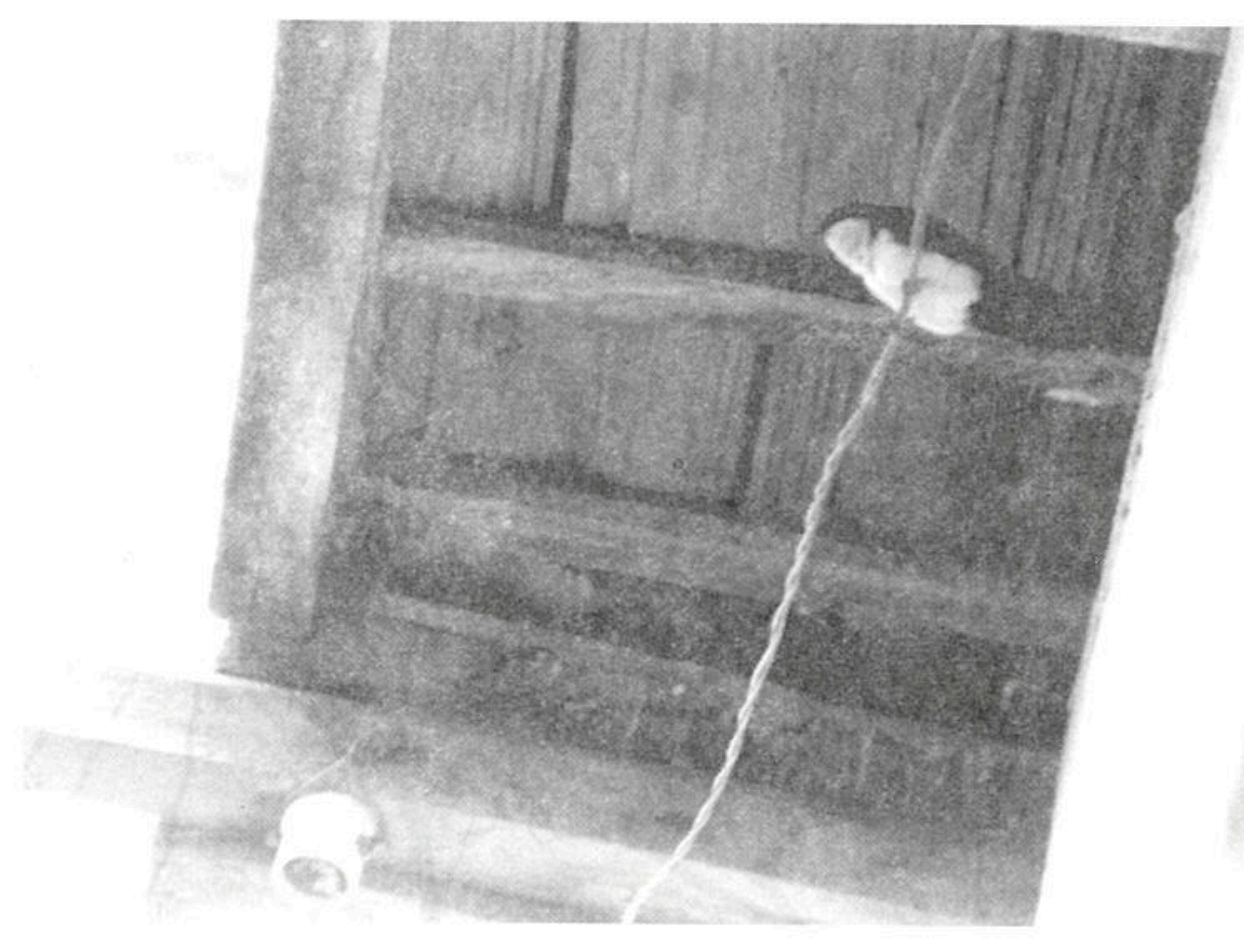

8. Andorinha

Fot. RENATO A. M. SILVANO 


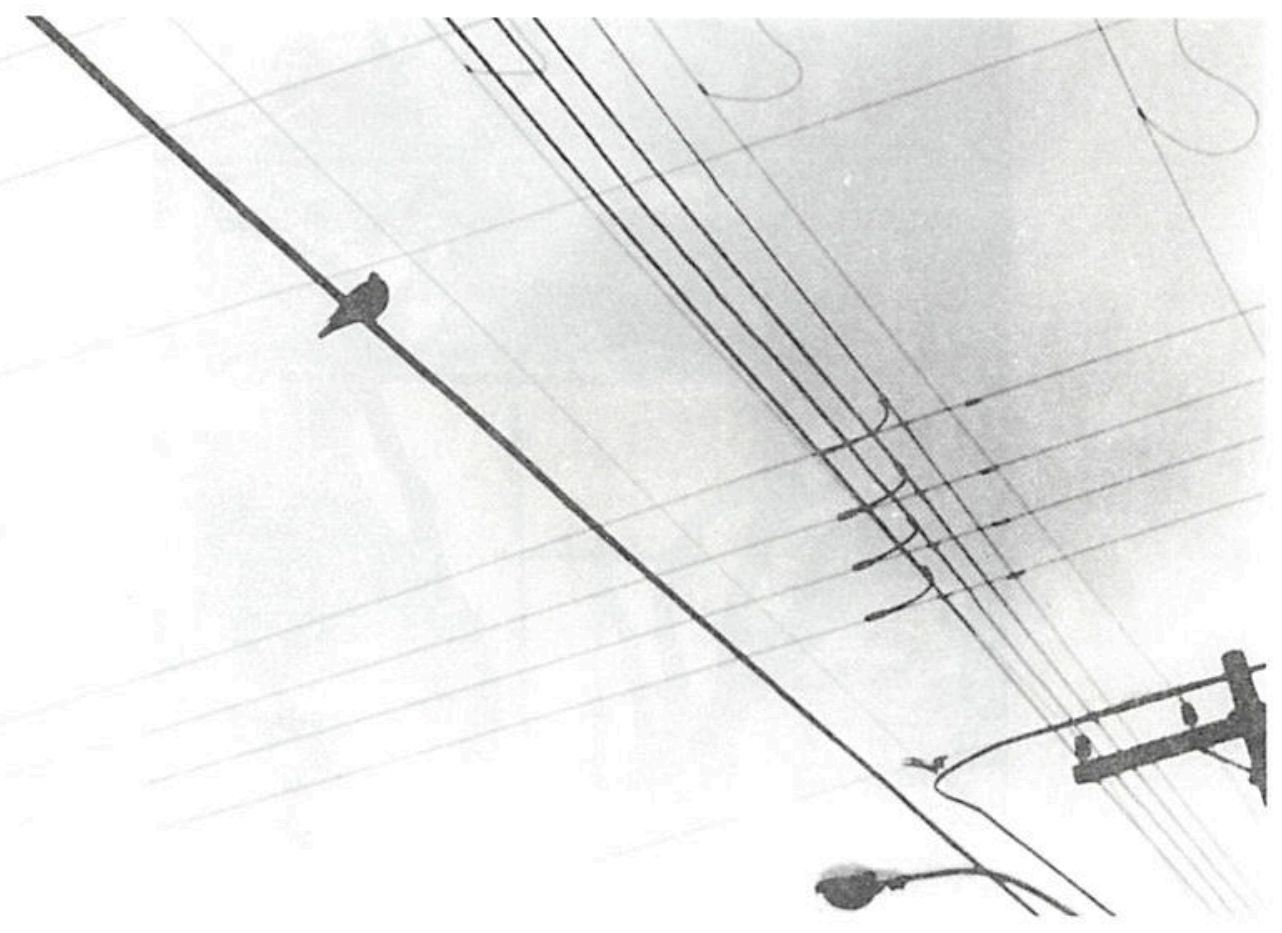

9. Fot. ANTÔNIO CARLOS CÂNDIDO 


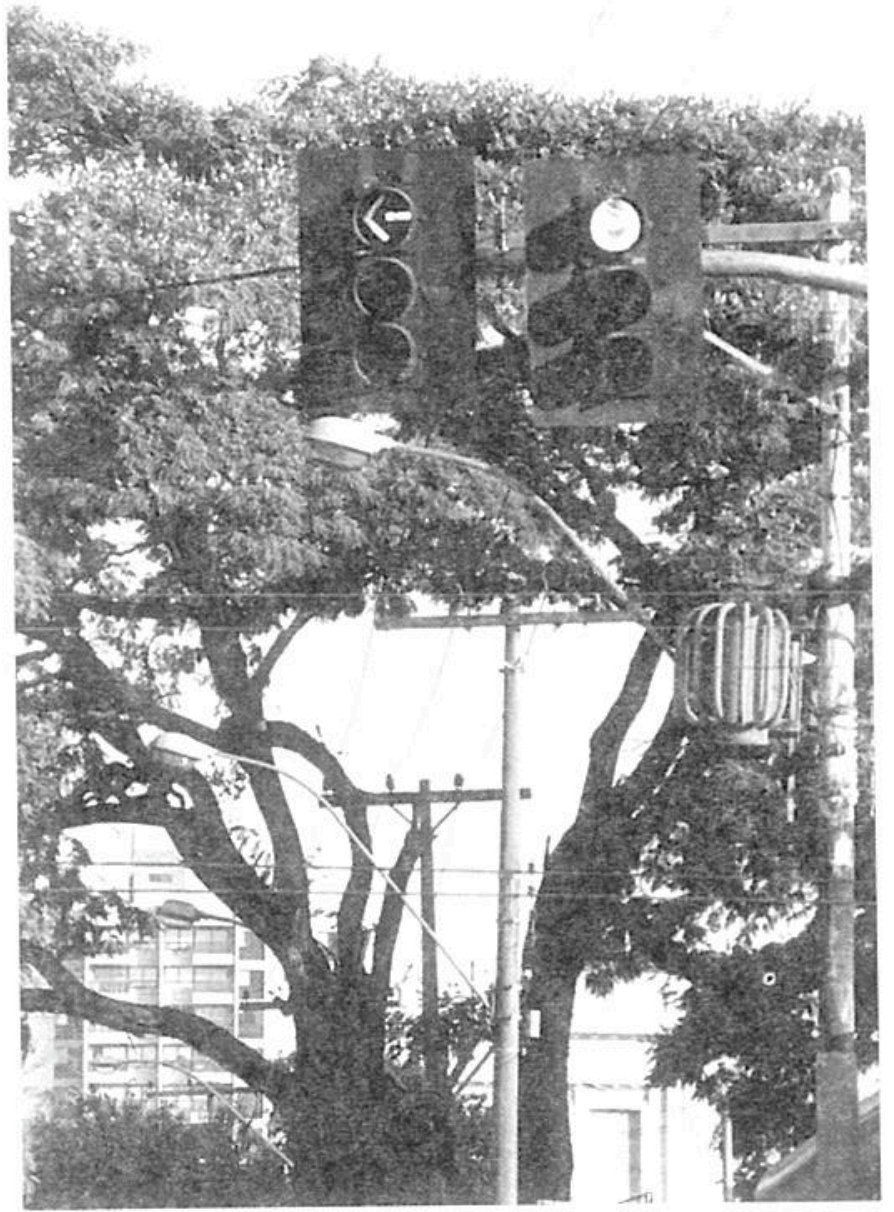

10. Fot. SILNEI MARTINS 


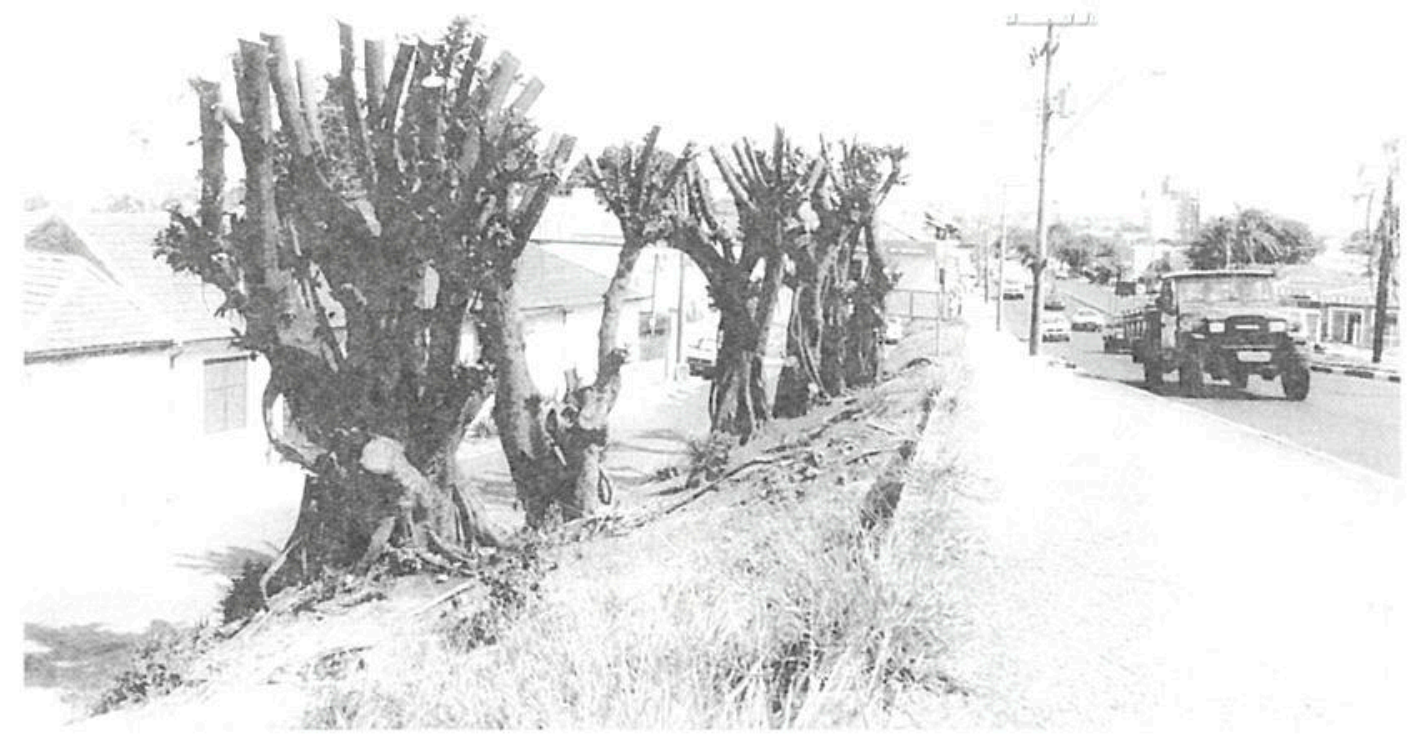

11. Fot. RENATO MERCURY 


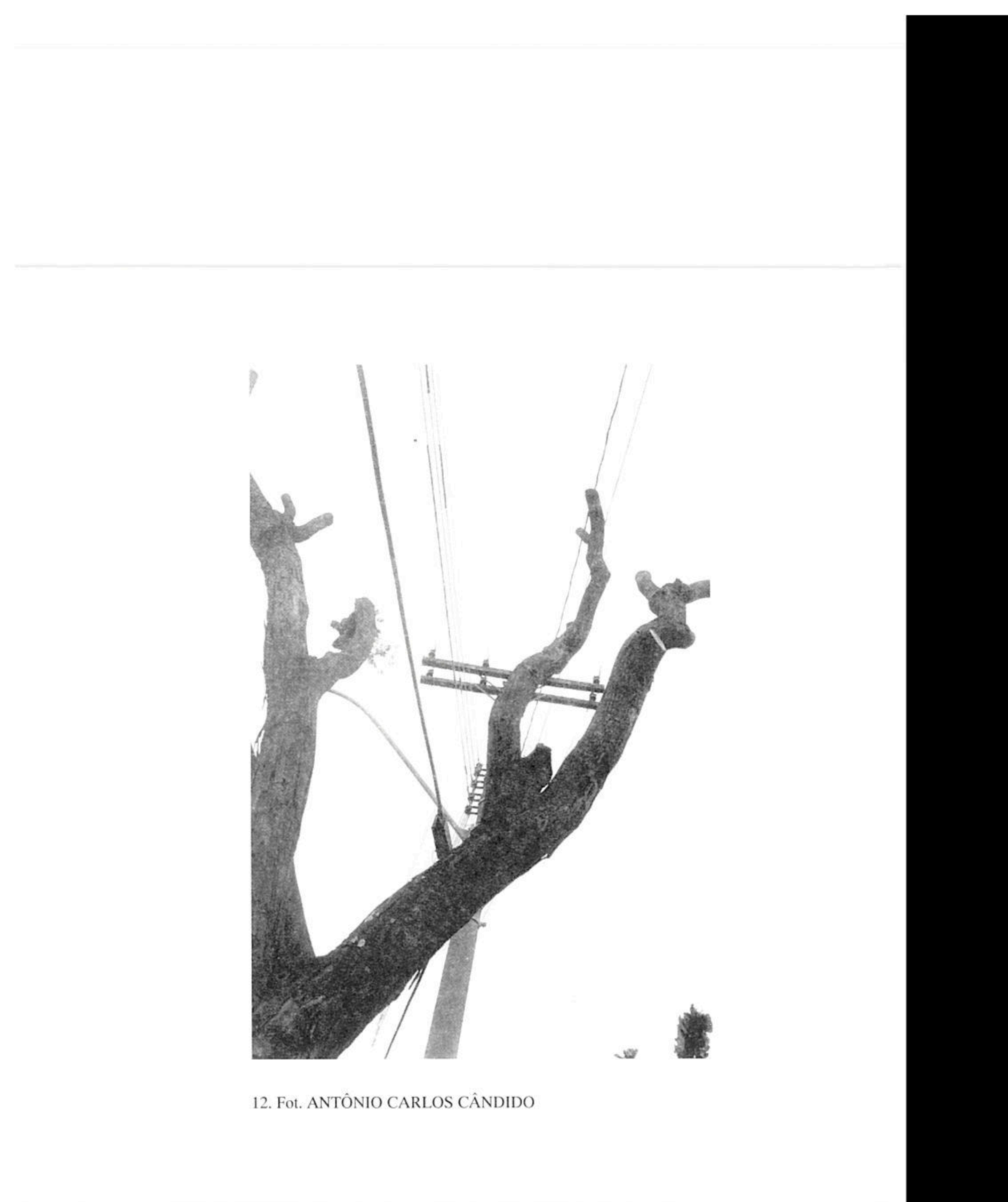




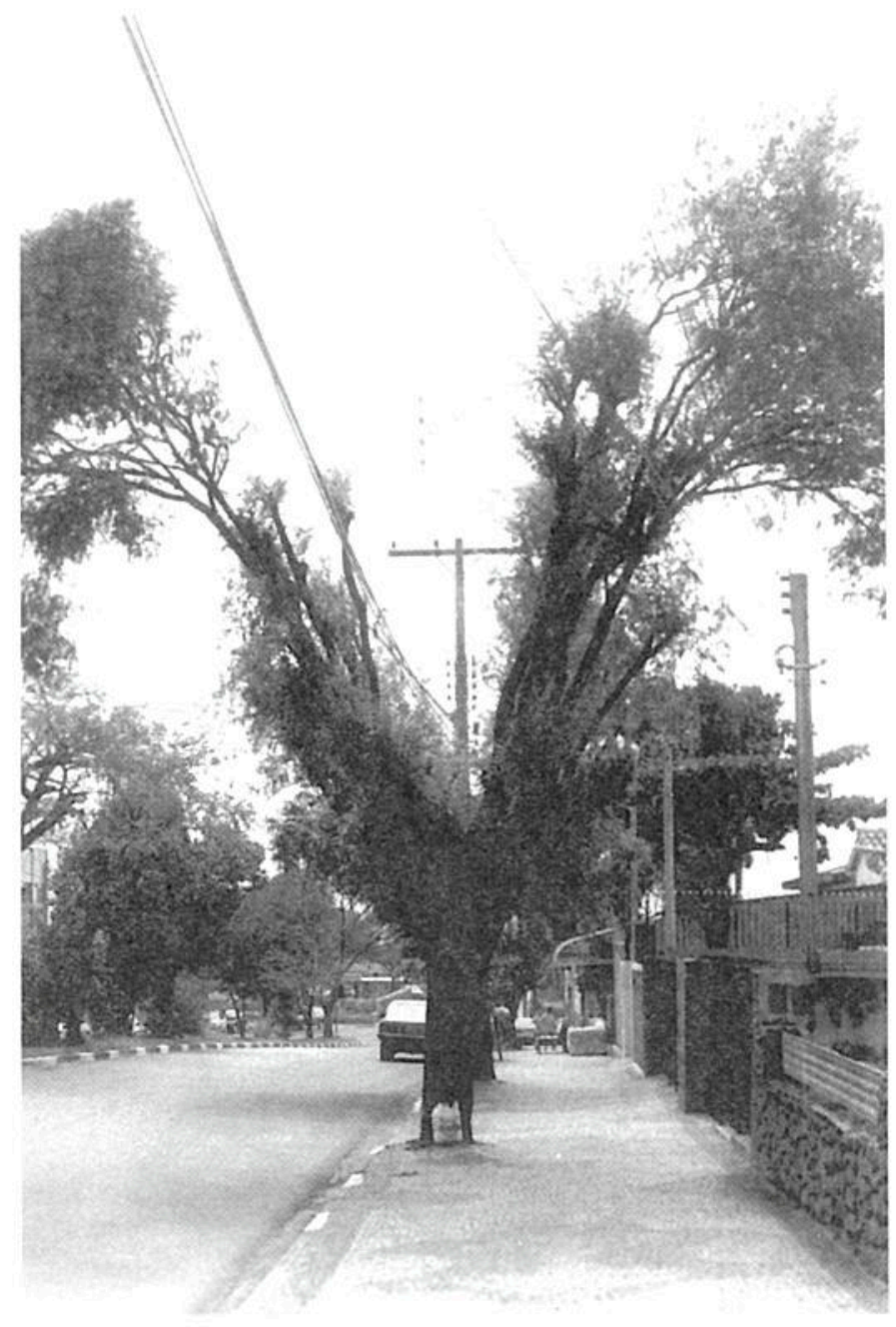

13. Fot. ROBERTO MERCURY 


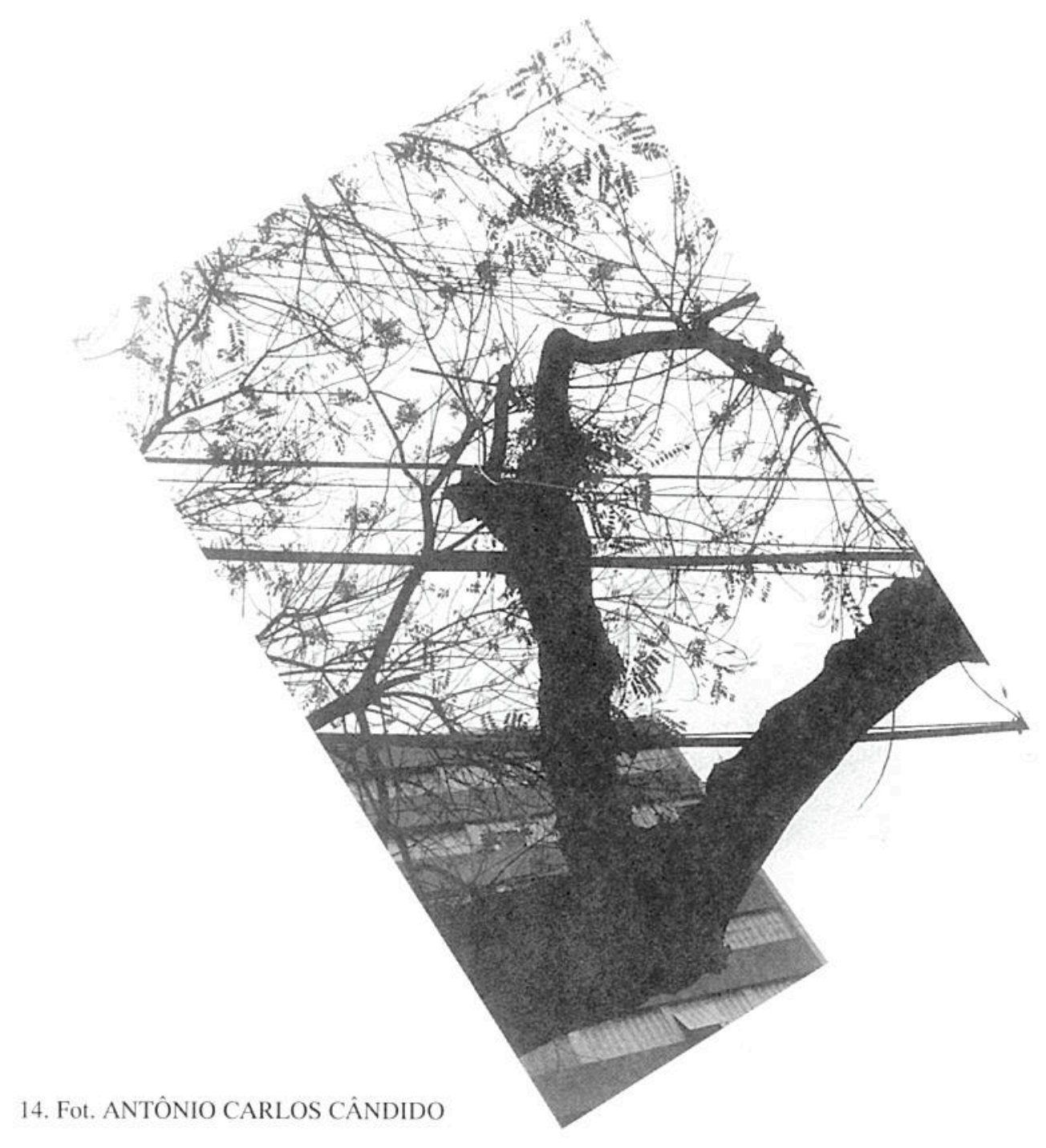



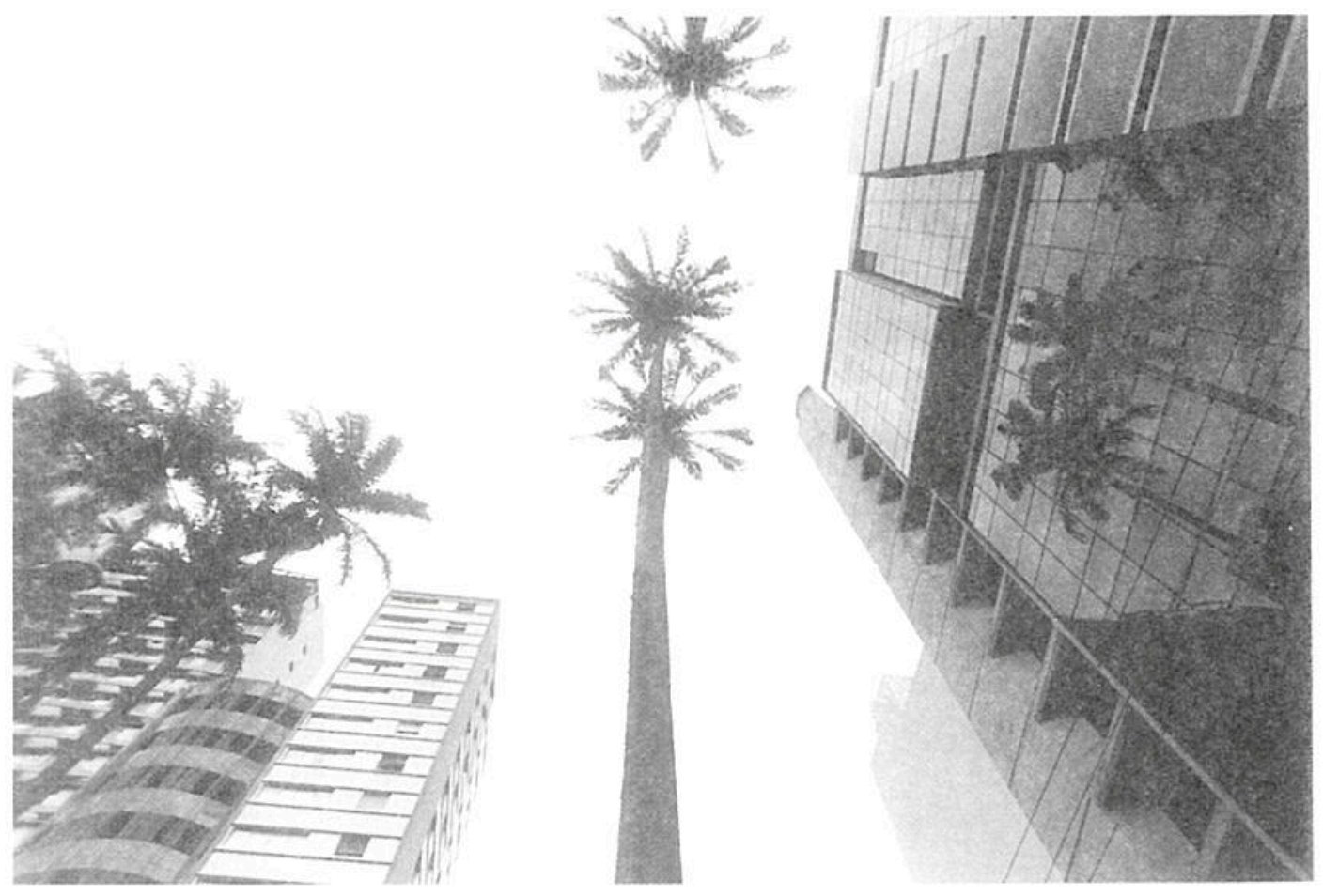

15. Fot. SILNEI MARTINS 